\title{
Cross-sectional population based study examining the impact of children with asthma on US rural families
}

\author{
Laura C. Palombi ${ }^{1}$, May Nawal Lutfiyya ${ }^{2 *}$, Kathryn J. Pederson ${ }^{3}$, David R. Simmons ${ }^{3}$, \\ Darin J. Steenerson ${ }^{1}$, Kenzie G. Hohman ${ }^{3}$, Krista Huot ${ }^{4}$ \\ ${ }^{1}$ Ambulatory Care Residency Program, College of Pharmacy, University of Minnesota, Minneapolis, USA \\ ${ }^{2}$ Essentia Institute of Rural Health, Duluth, USA; ${ }^{*}$ Corresponding Author: mlutfiyya@eirh.org \\ ${ }^{3}$ Essentia Health Acute Care Pharmacy Residency, Duluth, USA \\ ${ }^{4}$ Essentia Health System, Ambulatory Care Pharmacy Services, Duluth, USA
}

Received 16 December 2012; revised 17 January 2013; accepted 24 January 2013

\section{ABSTRACT}

Introduction: Approximately 7.1 million US children have asthma. The burden of asthma is disproportionate with rural US populations experiencing a higher prevalence of the disease. Rural populations experience additional disparities regarding health care access, job availability, and daily living resources. Hence, the family impact of having a child with asthma may be influenced by geographic locale. This impact could be a result of health insurance tied to employment, out of pocket costs, and health care provider availability. Few studies have assessed the impact a child's asthma has on a family. This study sought to answer the question: What is the impact of children with asthma on US rural families? Methods: Multivariate techniques were performed to examine a single year of data from two connected population-based datasets, the 2007-2008 National Survey of Children's Health and the 2009-2010 Children with Special Health Care Needs Survey. Children with current asthma defined the study population for both datasets. A logistic regression model was performed for each database. The dependent variable for the first model was child in family currently has asthma, for the second it was rural children with current asthma. Results: The first logistic regression model confirmed that rural children were more likely to have asthma than non-rural children. The second logistic regression model yielded that rural families with a child diagnosed with asthma had greater odds of: not having health insurance, having a parent who stopped working, avoided a job change, or experienced financial problems because of the child's health.
Conclusions: This study demonstrated that rural families experience a disproportionate financial hardship as a result of their child's asthma. Pharmacist intervention in asthma care in rural areas has the potential to decrease the financial burden for a family while also improving a child's health.

Keywords: Asthma Family Burden; Children with Asthma; Rural Children with Asthma; NSCH Data; CSHCNS Data

\section{INTRODUCTION}

Asthma is defined as a chronic respiratory condition characterized by episodes or attacks of inflammation and narrowing of small airways in response to asthma triggers [1]. Triggers can include respiratory infections, allergens, pollutants, changes in temperature and excitement/stress [2]. An estimated 7.1 million children living in the United States have asthma [2]. Asthma is a critical medical and public health problem that has been increasing in prevalence since 1980 [3-6]. Currently, the prevalence of childhood asthma is $11.8 \%$ in the US [2]. In 2007 , there were over 457,000 all age asthma-related hospitalizations [3]. In 2006, $13.5 \%$ of all pediatric hospitalizations (excluding newborns) were asthma-related [7].

Asthma continues to be one of the top five most expensive diseases for the US healthcare system [8]. The direct annual cost of asthma for school-aged children has been estimated at $\$ 1009.8$ million, or $\$ 401$ per US school-aged child while the annual indirect cost has been estimated at $\$ 983.8$ million or $\$ 390$ per US school-aged child [6]. Direct costs are driven by hospitalizations and medications with work and school losses accounting for the largest components of indirect costs [9]. 
In the US, the burden of asthma is disproportionate. Clement et al. (2008) described demographic and healthservice-related contributory factors that might account for differences in the prevalence and health outcomes related to asthma [10]. These factors include geographic locale, sex, environmental factors, low socioeconomic status, lack of health insurance, poorer access to asthma specialists, inappropriate use of health care resources, and inadequate medical care [10]. There is strong evidence that asthma has a higher prevalence in rural populations [1,3,11]. Furthermore, Probst, et al. (2004) reported that health disparities among rural minority populations were more severe than among urban minorities for a number of health-related conditions [12].

The family impact of having a child with asthma may vary greatly depending on any number of variables including how well the condition is controlled, access to primary care and health insurance coverage, as well as other resources such as employment and household income. The impact of a child's asthma on a family not only entails out-of-pocket costs for medications and transportation challenges in accessing necessary care, but also may influence work-related choices that parents make, such as avoiding job changes so as not to lose health insurance coverage or stopping work in order to accommodate a child's health.

Few studies have assessed the impact that a child's asthma has on a family. A small cross-sectional study conducted in Detroit highlighted the impact of financial burden on low-income urban families who had children with asthma [13]. However, the findings lack generalizability in part because of the small number of families surveyed in a limited geographic location. For instance, family impact may differ depending on whether a family resides in a rural or non-rural area of the US. This impact could be a result of health insurance tied to employment, out of pocket costs tied to health insurance plans, and availability of health care providers. In order to fill an epidemiological knowledge gap and gain generalizability, we analyzed population-based data representative of the US child population with asthma. Our focus was on rural families because of the elevated prevalence of asthma and known health disparities among those populations. The objective of this study was to determine the financial and employment impact on US rural families with at least one child with asthma.

\section{METHODS}

The NSCH and CSHCNS and the Study Population. Two databases were used in this study. The 2007-2008 National Survey of Children's Health (NSCH) and the 2009-2010 Children with Special Health Care Needs Survey (CSHCNS) were examined using bivariate and multivariate analysis strategies. The NSCH is a US population-based survey providing a broad range of information about children's health and well-being collected in a manner that allows for comparisons among US states and at the national level. It is a random-digitdial survey conducted by the Centers for Disease Control and Prevention's (CDC) National Center for Health Statistics. Telephone numbers are called at random to identify households with one child or more 17 years of age and younger. Once identified, one child is randomly selected to be the subject of an interview with the parent or guardian in the household who is the most familiar with the targeted child. Collected data are weighted, nationally and by US state, to represent the population of noninstitutionalized children 17 years old or younger. The CSHCNS is a survey of a subset of the NSCH. This population-based survey has the primary goals of assessing the prevalence and impact of special health care needs children in the US. This survey collects data on variables related to medical homes, health insurance status, access to needed services, adequate care coordination, and parent's satisfaction with their child's health care. Data are also collected on functional difficulties, transition services, and questions pertaining to specific sub-populations. Just as with the $\mathrm{NSCH}$, interviews are conducted with parents or guardians who are most familiar with the child's health.

A single year of data from each of these databases was analyzed. Children with current asthma defined the study population for both datasets. Before being asked if the child currently had asthma, the interviewee was asked if a health care provider had ever diagnosed the child with asthma. All analyses were conducted on weighted data. The weighting variable used for analyses was calculated by the CDC using the most recently available census data to provide a stratified representation of the nation's children. A full description of the NSCH and the development of sampling frames have been previously described [14]. A number of the variables used in this study were either computed or re-coded for analysis. Table 1 displays the variables, original survey questions used, and the re-coded categories from each of the databases used for this research.

Covariates. NSCH database covariates for the analysis included race/ethnicity, household income, geographic place of residency, sex, asthma severity and general health status. Out of pocket cost for those children with health insurance was also included in the analyses as well as usual place for child's medical care, having a health care provider, receipt of all needed health care in the past 12 months, and health care provider visit in the past 12 months. The additional CSHCNS covariates included in this study were amount of out of pocket costs, stopped working because of child's health, avoided a job change because of child's health, and financial problems 
Table 1. Original survey question and response categories with re-coded response categories 2007-2008 NSCH data and 2009-2010 CSHCN data.

\begin{tabular}{|c|c|c|}
\hline Survey Question & $\begin{array}{l}\text { Original Response } \\
\text { Categories }\end{array}$ & Re-coded Response Categories \\
\hline \multicolumn{3}{|c|}{ 2007-2008 NSCH Data } \\
\hline Selected child's (S.C.) age in years & $0-17$ Years & $\begin{array}{l}0-4=<5 \text { years } \\
5-17=\geq 5 \text { years }\end{array}$ \\
\hline Sex of S.C. & $\begin{array}{l}\text { Male } \\
\text { Female } \\
\text { Don't Know } \\
\text { Refused }\end{array}$ & Male Female \\
\hline In general, how would you describe S.C.'s health? & $\begin{array}{l}\text { Excellent } \\
\text { Very Good } \\
\text { Good } \\
\text { Fair } \\
\text { Poor }\end{array}$ & $\begin{array}{c}\text { Good, Very Good, Excellent = Good to } \\
\text { Excellent } \\
\text { Fair and Poor = Fair to Poor }\end{array}$ \\
\hline $\begin{array}{l}\text { Has a doctor or other health care provider ever told you that S.C. had } \\
\text { Asthma? }\end{array}$ & $\begin{array}{l}\text { No } \\
\text { Yes } \\
\text { Don't Know } \\
\text { Refused }\end{array}$ & $\begin{array}{l}\text { No } \\
\text { Yes }\end{array}$ \\
\hline Does S.C. currently have Asthma? & $\begin{array}{c}\text { No } \\
\text { Yes } \\
\text { Don't Know } \\
\text { Refused }\end{array}$ & $\begin{array}{l}\text { No } \\
\text { Yes }\end{array}$ \\
\hline Would you describe S.C asthma as mild, moderate, or severe? & $\begin{array}{l}\text { Mild } \\
\text { Moderate } \\
\text { Severe } \\
\text { Don't Know* } \\
\text { Refused }\end{array}$ & $\begin{array}{l}\text { Mild } \\
\text { Moderate } \\
\text { Severe }\end{array}$ \\
\hline $\begin{array}{l}\text { Does S.C. have any kind of health care coverage, including health insurance, } \\
\text { prepaid plans such as HMOs, or government plans such as Medicaid? }\end{array}$ & $\begin{array}{l}\text { No } \\
\text { Yes } \\
\text { Don't Know* } \\
\text { Refused* }\end{array}$ & $\begin{array}{l}\text { No } \\
\text { Yes }\end{array}$ \\
\hline $\begin{array}{l}\text { Does S.C.'s health insurance offer benefits or cover services that meet his/her } \\
\text { needs? }\end{array}$ & $\begin{array}{l}\text { Never } \\
\text { Sometimes } \\
\text { Usually } \\
\text { Always } \\
\text { Don't Know* } \\
\text { Refused }\end{array}$ & $\begin{array}{c}\text { Never, Sometimes, } \\
\text { Usually = Does not always meet child's } \\
\text { needs } \\
\text { Always }=\text { Always meets child's needs }\end{array}$ \\
\hline $\begin{array}{l}\text { Does S.C.'s health insurance allow him/her to see the health care providers } \\
\text { he/she needs? }\end{array}$ & $\begin{array}{l}\text { Never } \\
\text { Sometimes } \\
\text { Usually } \\
\text { Always } \\
\text { Don't Know* } \\
\text { Refused" }\end{array}$ & $\begin{array}{c}\text { Never, Sometimes, } \\
\text { Usually }=\text { Does not always allow child to } \\
\text { see the health care providers needed } \\
\text { Always = Always allows child to see the } \\
\text { health care providers needed }\end{array}$ \\
\hline $\begin{array}{l}\text { Not including health insurance premiums or costs that are covered by } \\
\text { insurance, do you pay any money for S.C.'s health care? }\end{array}$ & $\begin{array}{c}\text { No } \\
\text { Yes } \\
\text { Don't Know* } \\
\text { Refused }\end{array}$ & $\begin{array}{l}\text { No } \\
\text { Yes }\end{array}$ \\
\hline $\begin{array}{l}\text { Is there a place that S.C. USUALLY goes when he/she is sick or you need } \\
\text { advice about his/her health? }\end{array}$ & $\begin{array}{c}\text { No } \\
\text { Yes } \\
\text { There is more than } \\
\text { one place } \\
\text { Don't Know } \\
\text { Refused }\end{array}$ & $\begin{array}{l}\text { No }=\text { No } \\
\text { Yes, There is more than one place }=\text { Yes }\end{array}$ \\
\hline
\end{tabular}




\section{Continued}

Derived-place of health care after back coding other place response

Do you have one or more persons you think of as S.C.'s personal doctor or nurse?

During the past 12 months, how many times did S.C. see a doctor, nurse, or other health care provider for preventive medical care such as a physical exam or well-child checkup?

During the past 12 months, was there any time when S.C. needed health care but it was delayed or not received?

Is S.C. of Hispanic or Latino origin?

Is S.C. White, Black or African American, American Indian, Alaska Native, Asian, or Native Hawaiian or other Pacific Islander?

Derived-poverty level of this household based on DHHS poverty guidelines-8 Categories

Out of Pocket Costs For Health Care--Not including health insurance premiums or costs that are covered by insurance, do you pay any money for [S.C.]'s health care?

Out of pocket costs reasonable

\section{Doctor's Office \\ Hospital Emergency Room \\ Hospital Outpatient \\ Department \\ Clinic or Health Center School \\ Friend/Relative}

Mexico/Other Locations Out of US Some Other Place

Does Not Go To One Place Most Often

Telephone Hotline, Nurse Advice Line

Don't Know

Refused $^{*}$

No

Yes

There is more than one person

$$
\text { Don't Know" }
$$

Refused $^{*}$

$$
\begin{gathered}
0 \text { - } 20 \text { times } \\
\text { Don't Know } \\
\text { Refused }
\end{gathered}
$$

$$
\begin{aligned}
& \text { No } \\
& \text { Yes } \\
& \text { Don't Know* } \\
& \text { Refused* }
\end{aligned}
$$

No

Yes

Don't Know*

Refused*

Response categories $=$ Yes, No,

Don't Know or Refused for each race.

Respondents were asked to indicate all racial categories that applied.

$<100 \%$ of FPL

$>100 \%$ to $<133 \%$ FPL

$>133 \%$ to $<150 \%$ FPL

$>150 \%$ to $<185 \%$ FPL

$>185 \%$ to $<200 \%$ FPL

$>200 \%$ to $<300 \%$ FPL

$>300 \%$ to $<400 \%$ FPL

$>400 \%$ FPL

No

$$
\text { Yes }
$$

Don't Know*

Refused $^{*}$

Never

Sometimes

Usually

Always

No Out of Pocket Costs

Don't Know*

Refused $^{*}$
Doctor's Office, Hospital

Outpatient, Clinic or Health Center

$=$ Doctor's Office or Clinic

Hospital Emergency Room $=\mathrm{ER}$

School, Friend/Relative,

Mexico/Other Locations

Out of US,

Some Other Place,

Does Not Go to One Place Most Often,

Telephone Hotline, Nurse Advice Line

$=$ No Usual Place of Care or Other

No

Yes, and There is more than one person $=$ Yes

$0=$ None

$1-20=$ At least Once

No

Yes

No

Yes

Caucasian

African American

Other/Multiracial

Categories $1-5=</=200 \%$

FPL

Categories $6-8=>2005$

FPL

No

Yes

Not Always Reasonable

Always Reasonable

No Out of Pocket Costs 
Amount of out of pocket cost
Stopped working because of child's health

Avoided job change

Financial problems caused by child's health
$>\$ 500$

$\$ 250-\$ 500$

$<\$ 250$

$\$ 0$

Don't Know*

Refused ${ }^{*}$

$\begin{array}{cc}\text { No } & \\ \text { Yes } & \text { No } \\ \text { Don't Know* } & \text { Yes }\end{array}$

Refused

Yes

Don't Know*

Refused $^{*}$

No

Yes

Don't Know

Refused $^{*}$
No
Yes

Yes

Nothing

$<=\$ 500$

$>\$ 500$

No

Yes

No

Yes

*The categories of don't know and refused were recoded as missing in all instances.

caused by child's health.

All race/ethnicity categories were computed as mutually exclusive entities. For example, all children coded as Caucasian had respondents who chose only White as their racial classification, likewise black for African American children, etc. If a respondent identified the child as Hispanic, they were classified by that ethnic category regardless of any additional racial classification. Household income was measured by calculating the percent of Federal Poverty Level (FPL) using stated income range and number of persons in the household. Our categories were recoded as $<200 \% \mathrm{FPL}$ and $>200 \%$ FPL.

The definitions for geographic place of residence were based on whether the respondent lived in or outside of a Metropolitan or Micropolitan Statistical Area (MSA). Those living within an MSA were considered non-rural residents, and those living outside an MSA were considered rural residents. These designations were made by the $\mathrm{CDC}$ and not changed. In some instances, to ensure the anonymity of individual respondents, the rural/nonrural designation was suppressed in the data set. This suppression occurred whenever the sum total population for all MSA areas in a given state was $<500,000$ persons or whenever the sum total population for all the nonMSA areas in a given state was $<500,000$ persons.

Analysis. Descriptive and multivariate techniques were used to analyze data examining the research question posed. Two logistic regression models were tested, the first using NSCH data and the second using CSHCNS data. For the first logistic regression model, the dependent variable was whether a family had a child with asthma. The second logistic regression model used rural residency as the dependent variable on a customized database constructed from the larger dataset and that included only children with current asthma and no other comorbidities. Each model used a different set of covariates. The first model, using the NSCH survey data, included the following covariates: child race and ethnicity, geographic locale, out of pocket costs for health care, health care provider, and child's sex. The second model, using CSHCNS data, included the following covariates: amount of out of pocket cost, insurance status, parent who stopped working because of their child's health, parents who avoided a job change because of their child's health, and parents who reported having financial problems caused by their child's health.

Statistical Package for Social Scientists (SPSS version 20.0, IBM, Chicago, Illinois) was used to complete all statistical analyses; $\alpha$ was set at $\mathrm{p}<0.05$. Consent for participation in the surveys was obtained from interview respondents as soon as it was determined that their household contained an age-eligible child. Institutional review board (IRB) human subjects' approval was sought and received from Essentia Health's IRB.

\section{RESULTS}

From the 2007-2008 NSCH dataset, 91,642 children aged 0 to 17 years participated in the survey. These were weighted to represent $73,758,616$ children. Of the study participants, 11,904 were identified as having asthma and were then weighted to represent $6,645,003$ children 0 17 years of age. Before being asked if the child currently had asthma, the interviewee representing the child was asked if a health care provider had ever diagnosed the child with asthma. Of those children $0-17$ years of age who reported a diagnosis of asthma, 7925 reported having current asthma and these survey participants were weighted to represent 5,986,076 children 0 - 17 years of age. Bivariate analysis revealed that rural children were 
more likely to currently have asthma than non-rural children (unadjusted OR $=1.193,95 \% \mathrm{CI}=1.189-1.197$ ).

Table 2 presents NSCH data describing the US population of children with a diagnosis of asthma that currently have asthma. Of note, $53.2 \%$ of children with current asthma lived in households with annual incomes $>200 \%$ FPL, $57.3 \%$ were male, $71.4 \%$ had asthma classified as mild, $93.7 \%$ had health insurance, $27.5 \%$ of parents reported that the child's health insurance did not always meet the child's health care needs, $57.2 \%$ of families with a child with asthma incurred out of pocket costs for related health care, and $69.3 \%$ of out of pocket costs were perceived as not always reasonable by the child's parent or guardian.

The first logistic regression model was performed on $\mathrm{NSCH}$ data and the results are presented in Table 3. The dependent variable for this model was current asthma and the population examined was children $0-17$ years of age. Five covariates were entered into the model. The analysis yielded that in contrast to Caucasian children, African American, other/multiracial, and Hispanic children had greater odds of having current asthma. Children with current asthma also had greater odds of having a health care provider and being male.

The second logistic regression model was performed on CSHCNS data and the results are presented in Table 4. The dependent variable for this model was rural families with children who currently have asthma. Five covariates were entered into this model. The analysis yielded that rural parents of children with asthma had higher odds of having given up employment because of the child's health, avoided job changes because of the child's health, and had experienced financial problems because of the child's health.

\section{DISCUSSION}

There were a number of important results yielded from this study. Among these were that rural children were more likely to currently have asthma than nonrural children confirming the importance of examining the impact that a child with asthma may have on their family. Furthermore, the analysis yielded that rural parents of children with asthma had higher odds of experiencing financial problems because of their child's health. Rural parents more frequently reported having given up employment because of the child's health or having avoided job changes because of the child's health.

These findings suggest that rural families who have at least one child with asthma experience a number of hardships related to their child's health. A child with uncontrolled asthma is more likely to miss school days and when a child misses school, at least one of their parents misses work to care for them. Controlling asthma is an important dimension for lessening some of the hard- ships families might experience. Pharmacist can play a role in assisting a child to achieve better control of their asthma.

Pharmacists, particularly in rural areas, may be the most accessible health care providers for families to contact for advice regarding their child's health. Rural pharmacists can educate children and families about appropriate medication use as well as proper inhaler and nebulizer techniques $[15,16]$. Furthermore, pharmacists can monitor how well a child is using their medication by monitoring refills and suggesting when it may be appropriate to consider step-down or step-up therapy. Pharmacists can also ensure that the child has an asthma action plan in place.

Additionally, pharmacists are in the ideal role to help with product selection based on cost as well as medication effectiveness. Finally, pharmacists can provide education and awareness regarding the identification and avoidance of asthma triggers.

Study Limitations. There are several limitations to this study. First, the survey questions pose a limitation because only those variables available from the survey questions could be used. Also, the survey is based on telephone-derived data and may be skewed because those who could not be reached by phone could not participate in the survey. For example, the widespread use of answering machines and caller ID allows people to filter their phone calls potentially leading to a passive refusal to participate in surveys such as the NSCH and CSHCNS. Of course, the use of answering machines and caller ID to filter out "unwanted" or "unfamiliar" callers is beyond the control of survey administrators.

The variables measuring impact on the family were available only in the CSHCNS database that is a subset of the NSCH database. The CSHCNS includes only children identified as having a special health care need; hence, comparisons could not be made with otherwise healthy children. Nevertheless, our analysis provides a starting point for identifying the impact asthma has on rural families.

\section{CONCLUSION}

Rural families experience more hardships such as financial burden when they have a child with asthma. As an accessible health care provider, pharmacists are wellpositioned to intervene to improve asthma care and lessen a family's burden. Further examination of the benefits of pharmacist intervention in rural communities is essential to improving patient care and decreasing family impact of asthma.

\section{ACKNOWLEDGEMENTS}

We are grateful for the thoughtful comments Drs. Andrine Lemieux and Daniel Saman made on earlier drafts of this paper. 
Table 2. Description of children with current asthma 2007 NSCH data (weighted $n=6,645,003$ ).

\begin{tabular}{|c|c|c|}
\hline Covariates & Factors & Percentages \\
\hline \multirow{2}{*}{ Household Poverty Level } & $<=200 \% \mathrm{FPL}$ & 46.8 \\
\hline & $>200 \% \mathrm{FPL}$ & 53.2 \\
\hline \multirow{2}{*}{ Child's Sex } & Male & 57.3 \\
\hline & Female & 42.7 \\
\hline \multirow{4}{*}{ Child Race And Ethnicity } & Caucasian & 52.7 \\
\hline & African American/Black & 26.3 \\
\hline & Other/Multiracial & 10.5 \\
\hline & Hispanic & 10.5 \\
\hline \multirow{2}{*}{ Age Group } & $<5$ Years & 17.7 \\
\hline & $5-17$ Years & 82.3 \\
\hline \multirow{3}{*}{ Mother's Education } & $<\mathrm{HS}$ & 11.3 \\
\hline & HS Graduate & 32.0 \\
\hline & $>$ HS Education & 56.7 \\
\hline \multirow{3}{*}{ Father's Education } & $<\mathrm{HS}$ & 10.8 \\
\hline & HS Graduate & 31.2 \\
\hline & >HS Education & 58.0 \\
\hline \multirow{2}{*}{ Primary Language Spoken at Home } & English & 94.8 \\
\hline & Language Other Than English & 5.2 \\
\hline \multirow{3}{*}{ Asthma Severity } & Mild & 71.4 \\
\hline & Moderate & 23.0 \\
\hline & Severe & 5.6 \\
\hline \multirow{2}{*}{ Out of Pocket Costs for Health Care } & No & 42.8 \\
\hline & Yes & 57.2 \\
\hline \multirow{3}{*}{ Out of Pocket Costs Reasonable } & Not Always Reasonable & 69.3 \\
\hline & Always Reasonable & 30.6 \\
\hline & No Out of Pocket Costs & .1 \\
\hline \multirow{3}{*}{ Place for Usual Care } & Doctor's Office or Clinic & 91.5 \\
\hline & Emergency Department & 3.7 \\
\hline & No Usual Place of Care & 4.8 \\
\hline \multirow{2}{*}{ Child's Health Status } & Good to Excellent & 88.8 \\
\hline & Fair to Poor & 11.2 \\
\hline \multirow{4}{*}{ Health Plan Allows Child to See All Needed Providers } & Child Has No Health Insurance & 6.3 \\
\hline & Child Has Health Insurance & 93.7 \\
\hline & Not Always & 18.8 \\
\hline & Always & 81.2 \\
\hline \multirow{2}{*}{ Health Plan Meets Needs } & Does Not Always Meet Child's Needs & 27.5 \\
\hline & Always Meets Child's Needs & 72.5 \\
\hline \multirow{2}{*}{ Needed Medical Care Not Received } & No & 88.2 \\
\hline & Yes & 11.5 \\
\hline \multirow{2}{*}{ Have Personal Health Care Provider } & Yes & 94.0 \\
\hline & No & 5.5 \\
\hline \multirow{3}{*}{ Health Care Provider Visit Past 12 Months } & No Visits & 6.9 \\
\hline & At Least One Visit & 91.8 \\
\hline & Unknown & 1.3 \\
\hline
\end{tabular}


Table 3. Logistic regression model for characteristics of children with a self-reported health care provider diagnosis of asthma with current asthma 2007-2008 NSCH data.

\begin{tabular}{ccc}
\hline Covariate & Factors & Adjusted Odds Ratio (95\% CI) \\
\hline Child Race and Ethnicity & Caucasian & $-^{*}$ \\
& African American/Black & $1.814(1.810,1.818)$ \\
& Other/Multiracial & $1.327(1.324,1.331)$ \\
Geographic Locale & Hispanic & $1.129(1.126,1.132)$ \\
& Non-Rural & $-^{*}$ \\
Out of Pocket Costs for Health Care & Rural & $1.089(1.086,1.091)$ \\
& No & $1.015(1.013,1.016)$ \\
Health Care Provider & Yes & $--^{*}$ \\
Child's Sex & Have Health Care Provider & $1.239(1.234,1.243)$ \\
\end{tabular}

Table 4. Logistic regression model of impact of children with asthma on rural families 2009-2010 CSHCNS data.

\begin{tabular}{ccc}
\hline Covariates & Factors & Adjusted Odds Ratio (95\% CI) \\
\hline Amount of Out of Pocket Cost & Nothing & $1.407(1.391,1.422)$ \\
Insurance & $<=\$ 500$ & $.925(0.916,0.934)$ \\
& No Insurance & $-^{*}$ \\
Stopped Working Because of Child's Health & Have Insurance & $1.074(1.060,1.090)$ \\
& No & $-^{*}$ \\
Avoided Job Change & Yes & $1.150(1.133,1.169)$ \\
& No & $--^{*}$ \\
Financial Problems Caused by Child's Health & Yes & $1.098(1.085,1.111)$ \\
\end{tabular}

\section{REFERENCES}

[1] Lutfiyya, M.N., McCullough, J.E. and Lipsky, M.S. (2012) Health service deficits and school-aged children with asthma: A population-based study using data from the 2007-2008 national survey of child health. Journal of the National Medical Association, 104, 275-285.

[2] American Lung Association (2012) Asthma and children fact sheet.

http://www.lung.org/lung-disease/asthma/resources/factsand-figures/asthma-children-fact-sheet.html

[3] Akinbami, L.J., Moorman, J.E. and Liu, X. (2011) Asthma prevalence, health care use, and mortality: United states, 2005-2009. National Health Statistics Report, 32

[4] Akinbami, L.J., Moorman, J.E., Garbe, P.L., Edward, J. and Sondik, E.J. (2009) Status of childhood asthma in the United States, 1980-2007. Pediatrics, 123, S131-S145. doi:10.1542/peds.2008-2233C

[5] Moorman, J.E., Zahran, H., Truman, B.I. and Molla, M.T. (2011) Current asthma prevalence-United States, 2006-2008. Morbidity and Mortality Weekly Report, 60, 84-86.

[6] Wang, L.Y., Zhong, Y. and Wheeler, L. (2011) Direct and indirect costs of asthma in school-age children. Preventing Chronic Disease.

http://www.cdc.gov/pcd/issues/2005/jan/04 0053.htm

[7] Stranges, E., Merrill, C.T. and Steiner, C.A. (2012) Hos- 
pital stays related to asthma for children, 2006. HCUP Statistical Brief \#58, August 2008. Agency for Healthcare Research and Quality, Rockville. http://www.hcup-us.ahrq.gov/reports/statbriefs/sb58.pdf

[8] Stanton, M.W. and Rutherford, M.K. (2005) The high concentration of US health care expenditures. Agency for Healthcare Research and Quality, Rockville. Research in Action Issue 19. AHRQ Pub. No.06-0060.

[9] Bahadori, K., Doyle-Waters, M.M., Marra, C., Lynd, L., Alasaly, K., Swiston, J. and FitzGerald, J.M. (2009) Economic burden of asthma: A systematic review. $B M C$ Pulmonary Medicine, 9, 24. doi:10.1186/1471-2466-9-24

[10] Clement, L.T., Jones, C.A. and Cole, J. (2008) Health disparities in the United States: Childhood asthma. The American Journal of the Medical Sciences, 335, 260-265. doi:10.1097/MAJ.0b013e318169031c

[11] Ownby, D.R. (2005) Asthma in rural America. Annals of Allergy, Asthma and Immunology, 95, S17-S22. doi:10.1016/S1081-1206(10)61005-8

[12] Probst, J.C., Moore, C.G., Glover, S.H. and Samuels,
M.E. (2004) Person and place: the compounding effects of race/ethnicity and rurality on health. American Journal of Public Health, 10, 1695-1703. doi:10.2105/AJPH.94.10.1695

[13] Patel, M.R., Brown, R.W. and Clark, N.M. (2012) Perceived parent financial burden and asthma outcomes in low-income, urban children. Journal of Urban Health: Bulletin of the New York Academy of Medicine.

[14] Blumberg, S.J., Foster, E.B., Frasier, A.M., et al. (2007) Design and operation of the national survey of children's health, 2007. Vital and Health Statistics, 1.

[15] Mehuys, E., Van Bortel, L., De Bolle, L., Van Tongelen, I., Annemas, L., Remon, J.P. and Brusselle, G. (2008) Effectiveness of pharmacist intervention for asthma control improvement. European Respiratory Journal, 31, 790-799. doi:10.1183/09031936.00112007

[16] Giraud, V., Allaert, F.A. and Roche, N. (2011) Inhaler technique and asthma: feasibility and acceptability of training by pharmacists. Respiratory Medicine, 105 , 11815-11822. doi:10.1016/j.rmed.2011.07.004 